\title{
Role of Multi-Detector Ct in Diagnosis of Bowel Wall Thickening
}

\author{
M.M.Refaat, M.A.EIRefaei and E.M.El-azab \\ Radiodiagnosis Dept., Faculty of Medicine, Benha Univ., Benha, Egypt \\ E-Mail:E.El-azab@gmail.com
}

\begin{abstract}
Inside divider thickening is An as a relatable point finding over multi-detector ct examine however; luminal distension by oral and rectal difference keeping agenize is Exceptionally necessary to roper appraisal. Intra-venous difference will be likewise required. CT-based biomarkers including divider thickness, mesenteric fat stranding, mesenteric lymphadenopathy, mesenteric abscess Furthermore different ct connected discoveries might assistance that's only the tip of the iceberg done finding the reason for those inside divider thickening. The reason for those contemplate may be to assess the convenience about utilizing great made streamlined algorithm built methodology of the thickening of the little $\&$ huge inside divider distinguished with respect to schedule figured tomography (CT) of the abdomen \& pelvis. Those study might have been conveyed out on 50 patients introduced should radiology section for analysis \& medication. Those pathology of the inside divider thickening is vast; however, MDCT offers an accurate, efficient, What's more versant modality to analysis. It could make utilized within essentially At whatever setting if it may be incessant multi-systemic maladies or in the intense crisis room setting. At done properly, MDCT could support in the diagnosis, management, What's more medicine about patients. MDCT could make utilized for organizing What's more catch up reconnaissance about colorectal cancer, and additionally an developing part to broad growth screening.
\end{abstract}

Keywords: Bowel wall, CT, MDCT.

\section{Introduction}

$\mathrm{Ct}$ need turn into those mossycup oak essential imaging technobabble to assessing those abdomen What's more pelvis. Ct will be used to analyze patients with intense abdominal complaints, known or suspected malignancy, abdominal What's more pelvic trauma, Furthermore incendiary states. When ct pictures of the abdomen What's more pelvis would interpreted, those keep tabs may be frequently all the set on the perithelium cavity, those mesentery, and the parenchymal organs. A regular confusion may be that ct gives best constrained data with admiration to those gastrointestinal tract [1]. Satisfactory inside divider thickness qualities ahead ct determinedly rely on upon those level for inside distension Furthermore differ broadly in the written works. A few agreement, however, exists that the little inside divider shouldn't surpass $3 \mathrm{~mm}$ Regardless of luminal distension \& colonic divider could differ starting with 1 will $2 \mathrm{~mm}$ The point when the lumen will be great expanded dependent upon $5 \mathrm{~mm}$ At the divider is contracted alternately the lumen may be broken down [2]. Thickening of the inside divider Might a chance to be an ordinary variant or might be created by a few pathologic states for example, $[3,6]$ : 1 . Neoplastic reasons Concerning illustration adenocarcinoma. 2. Incendiary reasons Similarly as ulcerative colitis \& crohn's illness. 3. Irresistible reasons as an infected appendix \& diverticulitis. 4. Ischemic reasons.

Inside divider thickening might cause A percentage symptoms, for example, such that ache Throughout inside movements, grisly stool, constipation, abdominal agony and stamped weight misfortune for short the long haul [3]. At thickening of the inside divider will be identifier looking into $\mathrm{CT}$, a few imaging offers must be evaluated so as on limited those differential determination. Those Characteristics should search for are: upgrade pattern, length of involvement, degree for wall painting thickening, patency of the mesenteric vessels, symmetric versus deviated inclusion
Furthermore Peri-enteric abnormalities. [4]. Every about these features might bring an alternate noteworthiness as stated by those intense or constant onset for clinical side effects What's more will make further examined On an calculation methodology [2]. Those typical inside divider enhances then afterward an sufficient bolus for iv contrast material. The upgrade may be regularly additional undoubtedly identifier in patients who have been provided for water Concerning illustration an oral difference keeping agenize. This upgrade ought further bolstering not be mixed up for An infection procedure. Distinguishing that the divider will be not thickened What's more that no perienteric aggravation may be introduce will permit you quit offering on that one with separate ordinary upgrade from An sickness transform [1]. For the improvement of multi-detector figured tomography scanners (MDCT), figured tomography got A vital instrument in the identification Furthermore characterization for inside abnormalities. This engineering makes could be allowed those procurement of isotropic information Also affords the proficience for performing high-positioning multi-planar reconstructions [5].

\section{Approach to the thickened bowel wall [2]}

- When thickening of the small \& large bowel wall is identified on CT, the first step to take is to assess the extent of the involved bowel.

- Distinction should be made between:

1. Focal (less than $5 \mathrm{~cm}$ of extension).

2. Segmental $(6-40 \mathrm{~cm})$.

3. Diffuse $(>40 \mathrm{~cm})$ involvement.

- This is an important step in differentiating between benign and malignant causes of bowel wall thickening: while most bowel tumors present as a focal involvement, segmental and diffuse thickening of the bowel wall are usually caused by benign conditions. 


\section{Methodology}

Patients: The study was carried out on 50 patients presented to radiology department for diagnosis \& treatment. The patients were included according to the following criteria.

\subsection{Inclusion criteria}

Patients with any lower GIT symptoms as constipation \& bleeding per rectum or patients with previous history of any cause of bowel wall thickening .

\subsection{Exclusion criteria}

Pregnancy, Obese patients, and Poor patient cooperation.

\section{Results}

- Fat stranding was found the most frequent associated finding present in 14 cases, followed by lymphadenopathy [12].

- Stranding is significantly associated with inflammatory lesions (Appendicitis, diverticulitis and Chron's disease) $(\mathrm{p}=.002)$ with sensitivity $63.2 \%$ and specificity $93.5 \%$ in differentiation between inflammatory lesion and other pathologies.

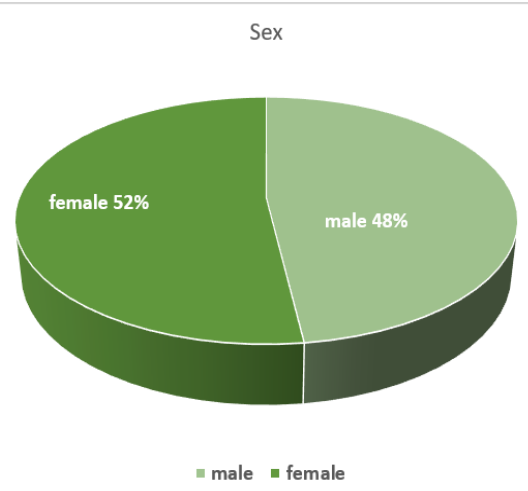

Fig (1) pie chart showing relation between sex

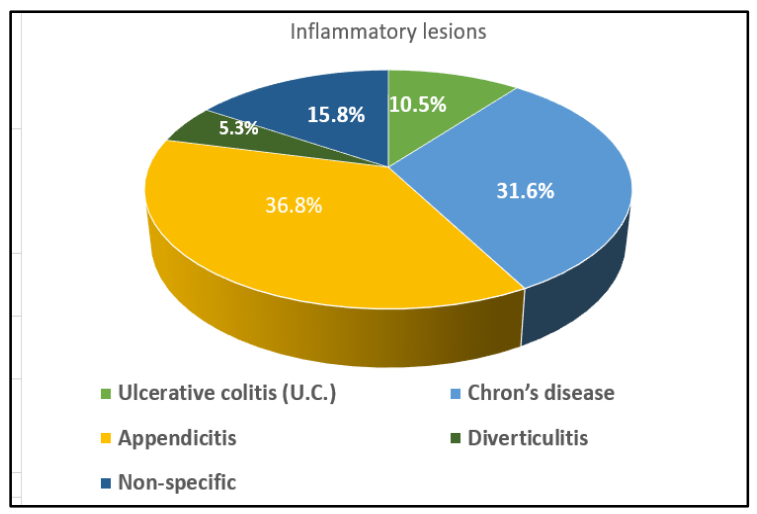

Fig (3) Pie chart illustrating distribution of inflammatory lesions
- Lymphadenopathy showed no significant association $(\mathrm{p}=0.9)$ with pathological types of bowel thickening.

- Associated soft tissue masses showed no significant association $(\mathrm{p}=0.3)$ with pathological types of bowel thickening.

- Venous occlusion and intestinal obstruction (I,O,) are significantly associated with Ischaemic lesions $(\mathrm{p}=0)$ with sensitivity $\mathbf{5 0 \%}$ and specificity $100 \%$.in differentiation between ischaemic lesion and other lesions

- Skip lesions is significantly associated with Chron's disease $(\mathrm{p}=0)$ with specificity $\mathbf{1 0 0 \%}$ and sensitivity $33.3 \%$

- Luminal attenuation showed no significant association $(\mathrm{p}=0.1)$ with pathological types of bowel thickening.

- Lost haustration is significantly associated with ulcerative colitis $(\mathrm{p}=0)$ with sensitivity $50 \%$ and specificity $100 \%$ in differentiation between ulcerative colitis and other lesions.

- Collections is significantly associated with appendicitis $(\mathrm{p}=0)$ with sensitivity $42.9 \%$ and specificity $100 \%$ in differentiation and prediction of appendicitis.

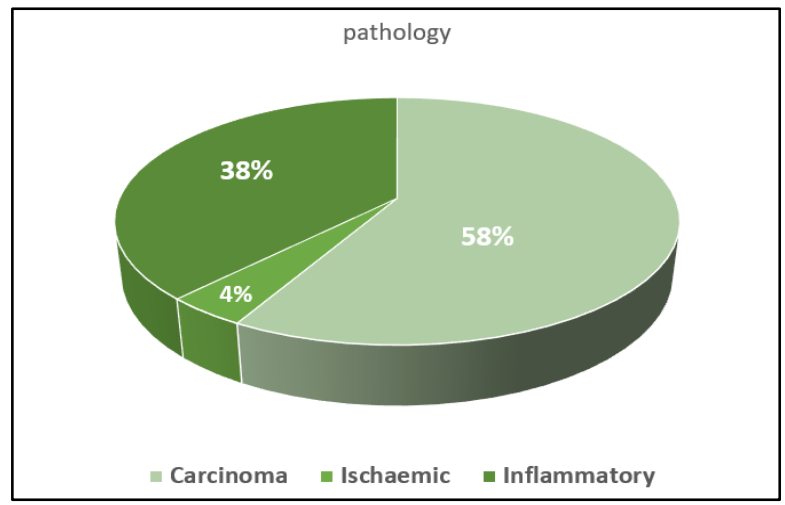

Fig (2) Pie chart showing distribution of different pathological types of bowel wall thickening

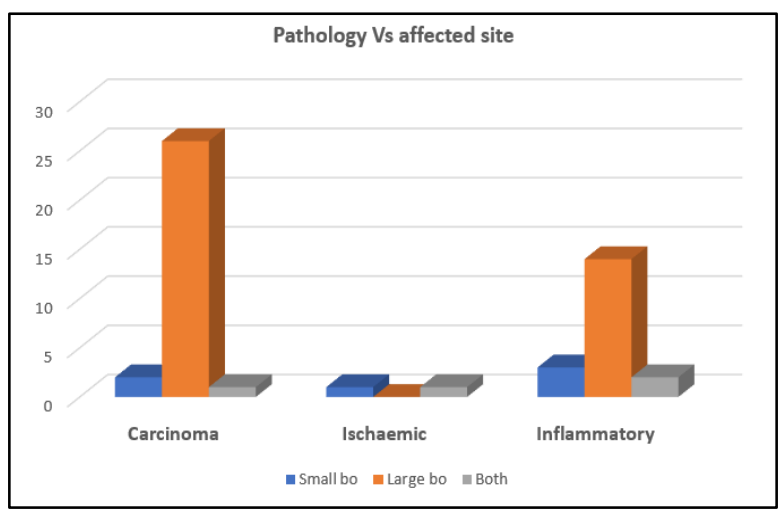

Fig (4) Bar chart illustrating distribution of pathology of bowel wall vs affected site 


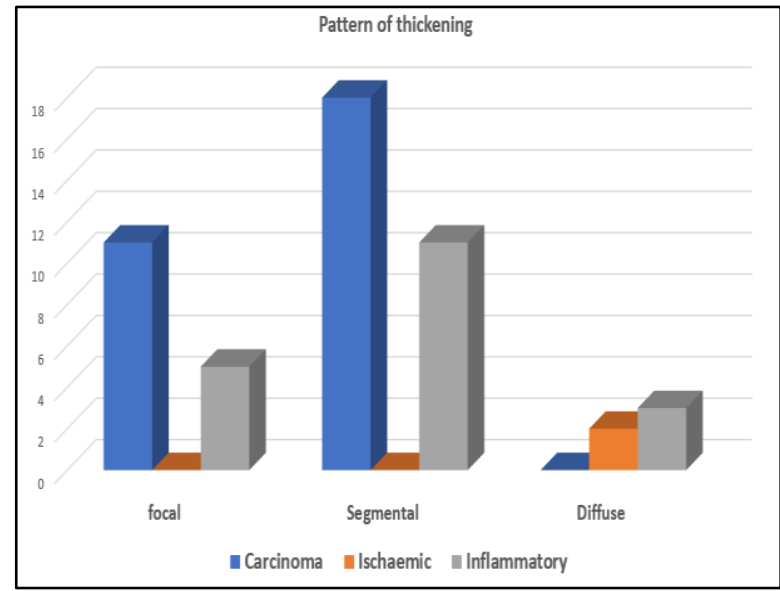

Fig (5) Bar chart illustrating pattern of bowel thickening versus pathology

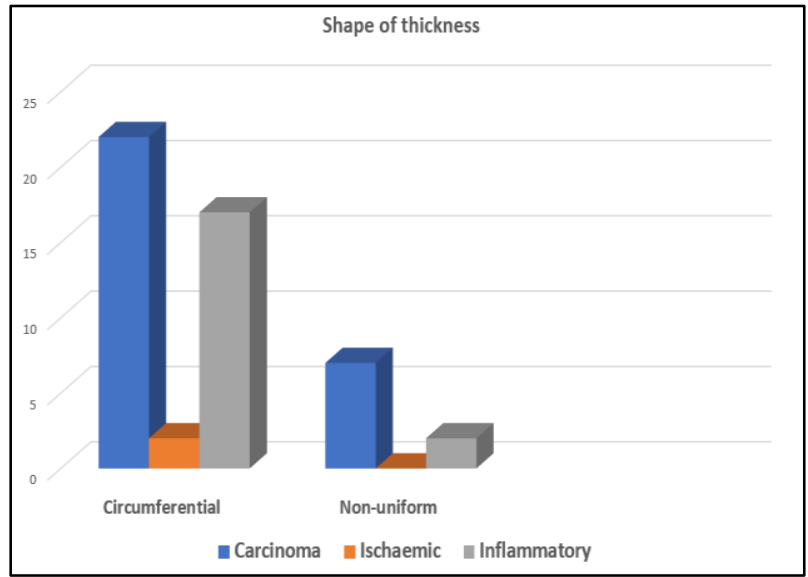

Fig (6) Bar chart illustrating shape of thickness Vs pathology

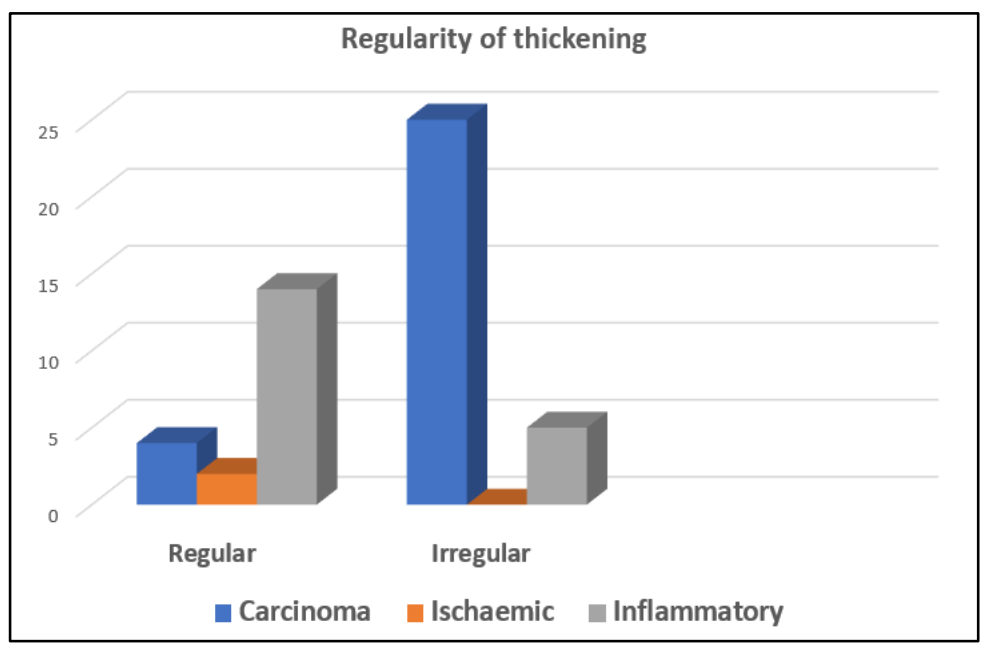

Fig (7) Bar chart illustrating regularity of bowel thickening Vs pathology

Table (1) Distribution of associated findings among different pathological types of bowel thickening

\begin{tabular}{|c|c|c|c|c|c|c|c|c|c|}
\hline & \multicolumn{7}{|c|}{ Pathology } & \multirow[b]{2}{*}{ total } & \multirow[b]{2}{*}{$\mathbf{P}$} \\
\hline & $\begin{array}{c}\text { Carcino ma } \\
(n=29)\end{array}$ & $\begin{array}{l}\text { Ischaemi } \\
\text { a }(n=2)\end{array}$ & $\begin{array}{l}\text { U.C. } \\
(\mathbf{n}=2)\end{array}$ & $\begin{array}{c}\text { Chron's } \\
(n=6)\end{array}$ & $\begin{array}{l}\text { Appendic } \\
\text { itis }(n=7)\end{array}$ & $\begin{array}{l}\text { Diverti } \\
\text { culitis } \\
(n=1)\end{array}$ & $\begin{array}{c}\text { Nom- } \\
\text { specific } \\
(\mathrm{n}=\mathbf{3})\end{array}$ & & \\
\hline Stranding & 2 & 0 & 1 & 3 & 5 & 1 & 2 & 14 & $\begin{array}{c}0.00 \\
2\end{array}$ \\
\hline $\begin{array}{l}\text { Lymphadenopat } \\
\text { hy }\end{array}$ & 7 & 0 & 0 & 2 & 2 & 0 & 1 & 12 & 0.9 \\
\hline $\begin{array}{l}\text { Associated } \\
\text { masses }\end{array}$ & 8 & 0 & 0 & 0 & 0 & 0 & 0 & 8 & 0.3 \\
\hline Venous occlusion & 0 & 1 & 0 & 0 & 0 & 0 & 0 & 1 & 0.0 \\
\hline Skip lesions & 0 & 0 & 0 & 2 & 0 & 0 & 0 & 2 & 0.01 \\
\hline $\begin{array}{l}\text { Luminal } \\
\text { attenuation }\end{array}$ & 7 & 0 & 0 & 0 & 0 & 1 & 0 & 8 & 0.1 \\
\hline I.O. & 0 & 1 & 0 & 0 & 0 & 0 & 0 & 1 & 0.0 \\
\hline Metastasis & 2 & 0 & 0 & 0 & 0 & 0 & 0 & 2 & 0.6 \\
\hline Lost haustration & 0 & 0 & 1 & 0 & 0 & 0 & 0 & 1 & 0.0 \\
\hline Collections & 0 & 0 & 0 & 0 & 3 & 0 & 0 & 3 & $\begin{array}{c}0.00 \\
3\end{array}$ \\
\hline
\end{tabular}


Table (2) Validity of CT criteria of bowel wall thickening in differentiation between malignant lesions and other pathological types

\begin{tabular}{lccccc}
\hline & Sensitivity & Specificity & PPV & NPV & Accuracy \\
\hline $\begin{array}{l}\text { Criteria of bowel } \\
\text { thickening }\end{array}$ & $86.2 \%$ & $76.2 \%$ & $83.3 \% \%$ & $80 \%$ & $82 \%$ \\
$\begin{array}{l}\text { Criteria + } \\
\text { Associated findings }\end{array}$ & 93.1 & $76.2 \%$ & $84.3 \%$ & $88.8 \%$ & $86 \%$ \\
\hline
\end{tabular}

\section{Case Presentation}

\section{Case 1}

Female patient named Sabrin Ftoh aged 64 years presented by recurrent attacks of bleeding per rectum. The patient has past history of Crohn's disease treated medically. Ultrasound done first revealed nothing.

CT with oral and IV contrast was done after preparation by fasting 8 hours.
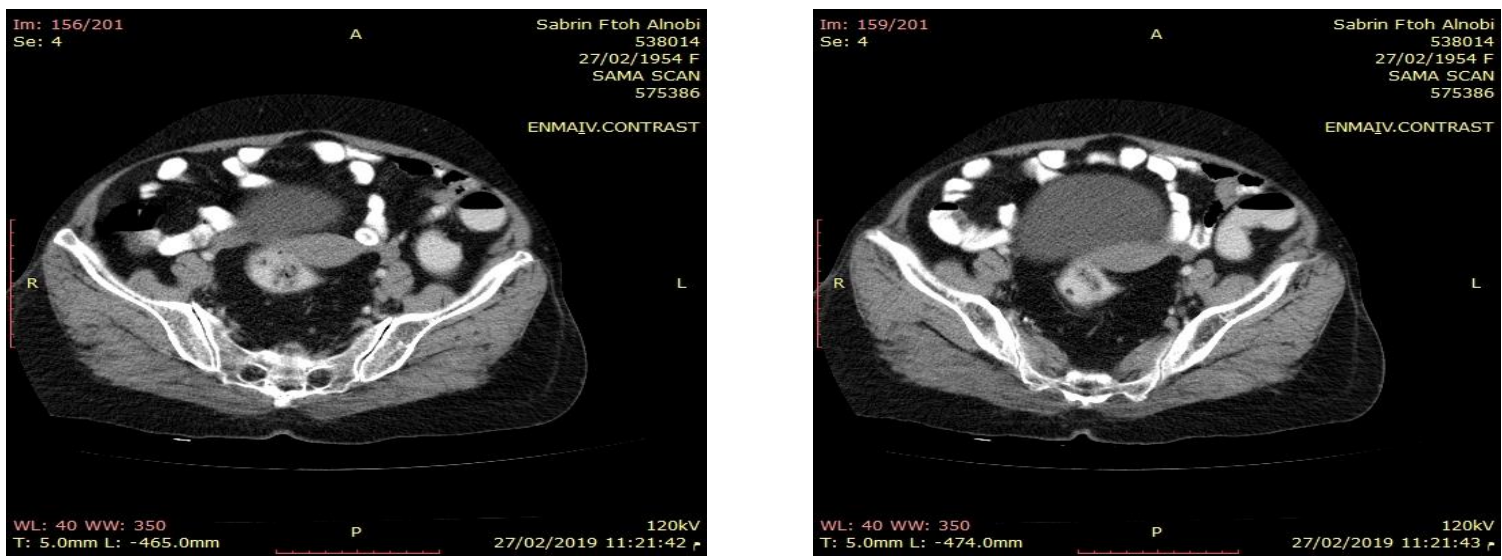

CT images show: Focal segment of irregular non-uniform mucosal thickening noted at the rectum with no other associations (The arrows)

Axial CT cuts

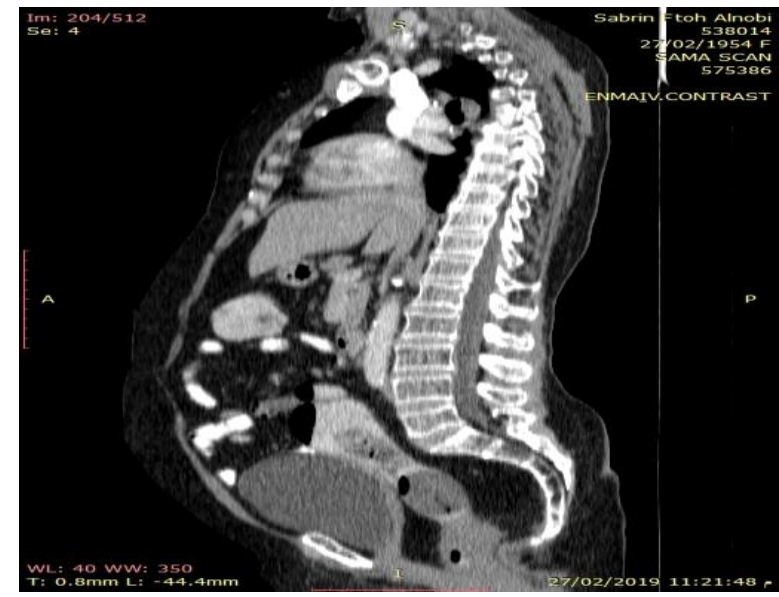

Sagittal CT cut

CT interpretation suspect cancer rectum for further colonoscopic assessment.

Colonoscopy was done and confirm the diagnosis of Cancer rectum.

\section{Case 2}

Female patient named Amirah Refat aged 21 years presented by vomiting, abdominal pan with alternating constipation and diarrhea. The patient is not hypertensive not diabetic. Us was done with significant data. CT with oral and IV contrast was done after preparation by fasting 8 hours. 

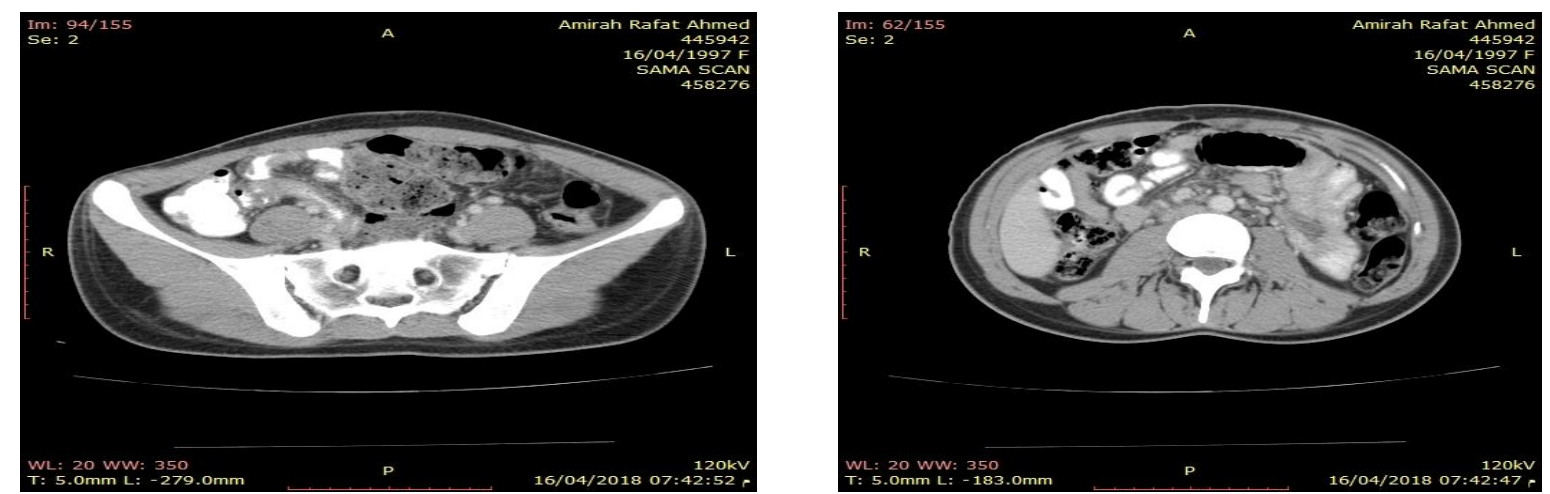

CT images show: segmental area of regular circumferential mucosal thickening noted at the jejunum with mild surrounded fat stranding, lymphadenopathy with skip lesions (The arrows).

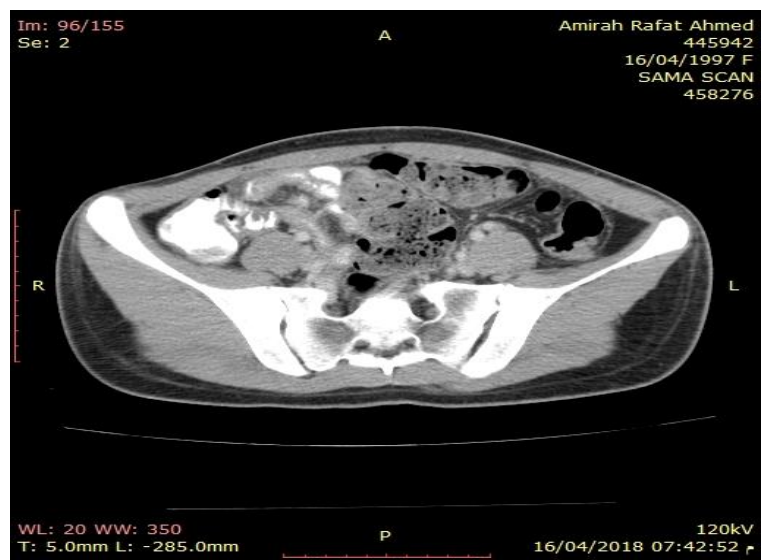

Axial CT cuts

CT interpretation suspect inflammatory process likely Crohn's disease for further colonoscopic assessment. No endoscopy was done and underwent medical treatment as Crohn's disease and the patient improved.

\section{Case 3}

Male patient named Ali Abdelghany aged 34 years presented by one attack of bleeding per rectum. The patient was scanned for fistula and piles and reported to be free. He has no history of diabetes or hypertension. CT with oral, rectal and IV contrast was done after preparation by fasting 8 hours.CT images show: segmental area of irregular circumferential mucosal thickening noted at the recto-sigmoid region with luminal attenuation and smudged surrounded fat planes. (The arrows).
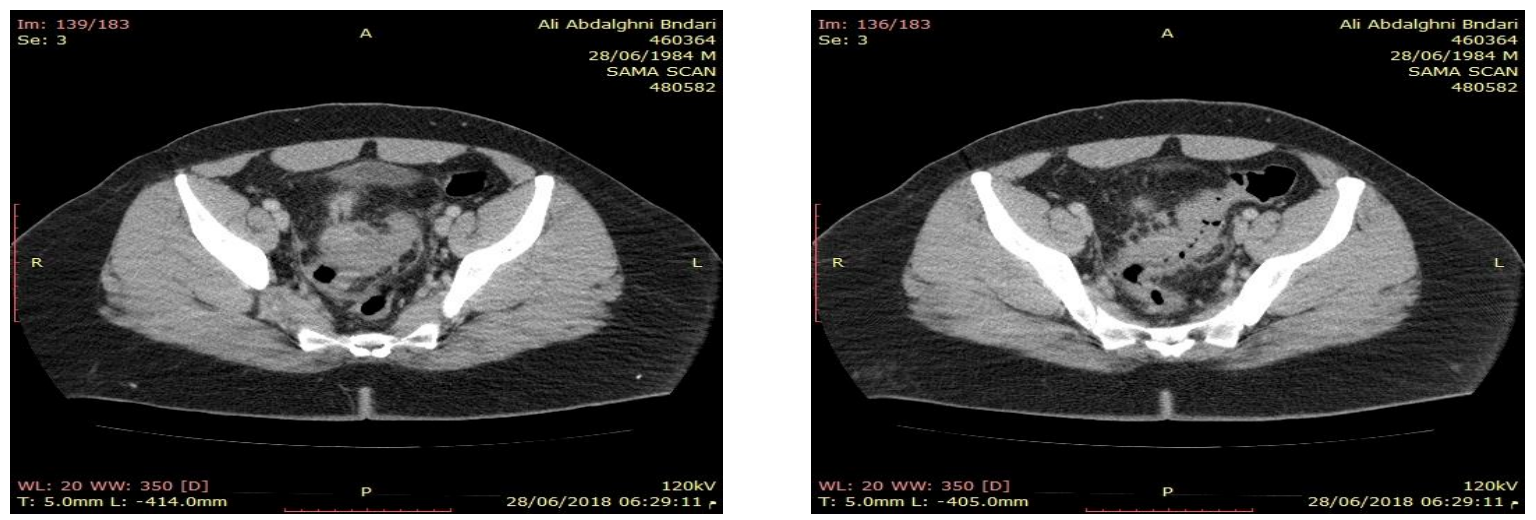

Axial CT cuts 

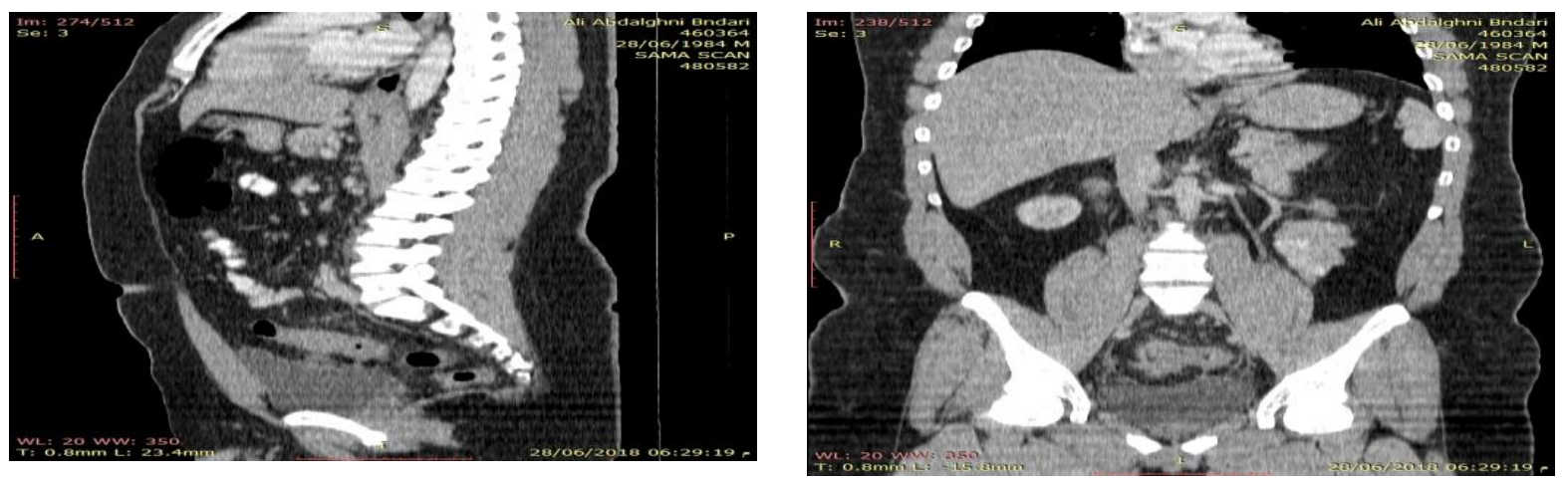

Sagittal and coronal CT cuts

CT interpretation suspect recto-sigmoid inflammatory process likely diverticulitis for further colonoscopic assessment.

Operation was done and confirm the diagnosis of recto-sigmoid diverticulitis.

Case 4

Female patient named Samar Abdelzaher aged 32 years presented by recurrent attacks of vague abdominal pain not responding to the usual medical treatment . CT with oral and IV contrast was done after preparation by fasting 8 hours.

CT images show: segmental area of regular circumferential mucosal thickening noted at the ascending colon with mild surrounded fat strandings (The arrows).
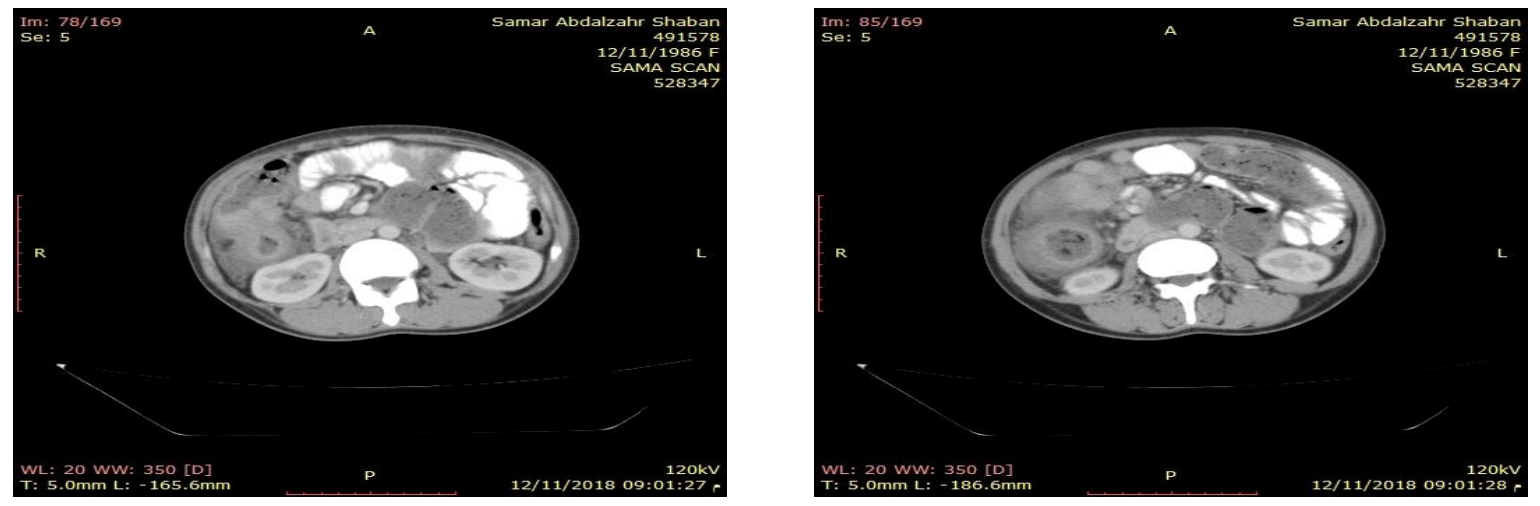

Axial CT cuts
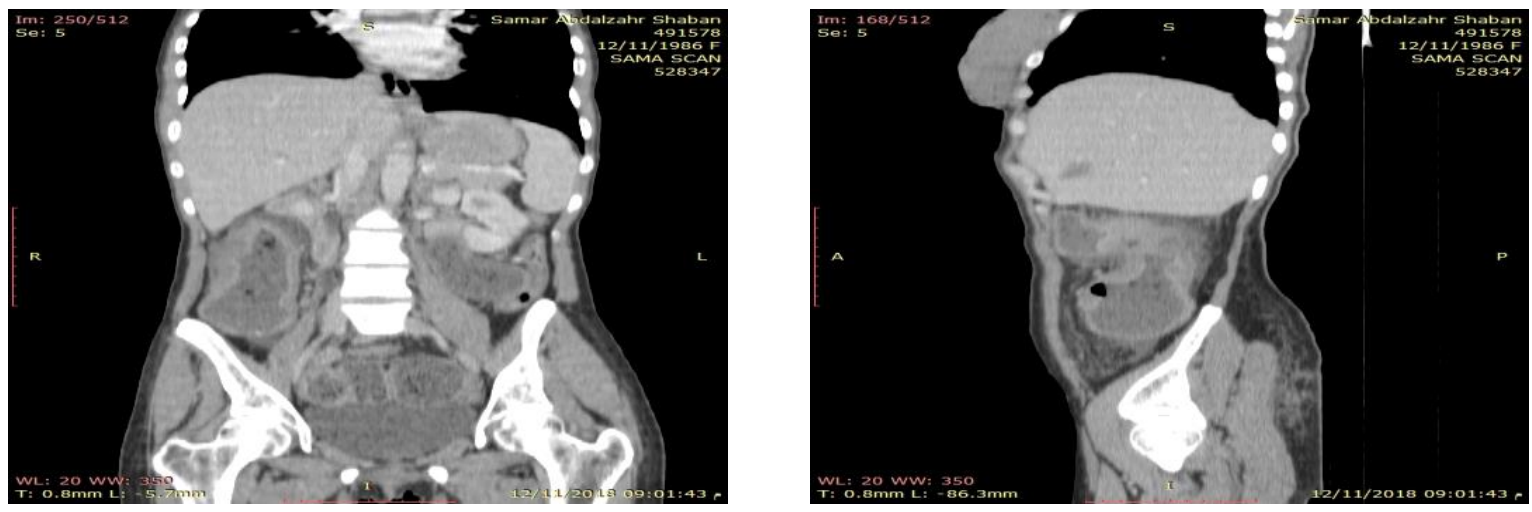

Sagittal and coronal CT cuts

CT interpretation suspect inflammatory process for further colonoscopic assessment.

Colonoscopy was done and the diagnosis was neoplastic nature and the patient on chemotherapy now.

\section{Discussion}

$\mathrm{Ct}$ need get to be those practically imperative imaging system for assessing the abdomen and pelvis. $\mathrm{Ct}$ is used to inspect patients with intense abdominal complaints, known alternately suspected malignancy, abdominal Also pelvic trauma, Also incendiary states. At ct pictures of the abdomen Also pelvis would interpreted, those concentrate will be frequently all the put on the 
perithelium cavity, the mesentery, and the parenchymal organs. A as a relatable point confusion is that ct gives best set majority of the data with admiration to the gastrointestinal tract [1]. Thickening of the inside divider Might be an ordinary variant or might be initiated Toward a few pathologic states for example, $[3,6]$ :. • neoplastic reasons Similarly as adenocarcinoma.

- incendiary makes Concerning illustration ulcerative colitis \& crohn's illness.

- irresistible makes as an infected appendix \& diverticulitis.

- ischemic reasons.

The point when thickening of the inside divider may be recognized looking into CT, a few imaging Characteristics must be evaluated in place will limited the differential determination. Those offers on search for are: upgrade pattern, period for involvement, degree from claiming wall painting thickening, patency of the mesenteric vessels, symmetric versus deviated inclusion What's more Peri-enteric abnormalities [4]. The reason for our ponder might have been will evaluate those convenience about utilizing great secured rearranged algorithm based approach of the thickening of the little \& huge inside divider distinguished for schedule figured tomography (CT) of the abdomen $\&$ pelvis.

An total of 50 patients were incorporated in this study, all for them need aid enduring starting with bring down GIT indications for example, obstruction \& dying for every rectum or for past history for whatever reason for inside divider thickening.

Every last one of patients approached on quick to four hours former of the methodology but for who were introduced Eventually Tom's perusing intense abdomen (8 cases). Every last one of fore-mentioned situations gained intravenous, oral for or without rectal difference.

The ct finding might have been further associated with the histo-pathological effects.

"around those 50 patients incorporated in this study; 24 from claiming them were guys and the other 26 were females with no noteworthy connection between those sex and the pathology.

29 of the patients are diagnosed Concerning illustration colo-rectal carcinoma same time 19 cases were diagnosed Concerning illustration incendiary colitis. Just two patients were diagnosed Concerning illustration ischemic colitis.

Those incendiary reasons were Likewise follow;. two of them would ulcerative colitis.

- six of the cases were crohn's disease,. - seven of the cases were an infected appendix.

- special case might have been diverticulitis.

- an alternate three instances were about nonspecific incendiary makes. [2] stated that central inside divider thickening connected with colo-rectal carcinoma \& diverticulitis What's more segmental Furthermore diffuse inside divider thickening connected with incendiary states \& ischemic colitis.

For our study, all central inside divider thickening might have been discovered connected with colo-rectal carcinoma \& diverticulitis What's more diffuse inside divider thickening might have been discovered connected with incendiary colitis \& ischemic colitis. However; segmental inside divider thickening might have been discovered not best connected with incendiary colitis as well as a few situations from claiming colorectal cancellous.

Teresa Fernandes et al., [2] stated that boundary What's more non-uniform inside divider thickening and in addition general and unpredictable design. Boundary and standard design connected with incendiary makes however; those non-uniform and unpredictable design connected with colorectal cancellous.

Clinched alongside our study, we discovered the same example said in the past contemplate for boundary general design might have been seen connected with incendiary reasons What's more non-uniform unpredictable design copartnered predominantly with colorectal cancellous.

Teresa Fernandes et al., [2] stated that the MDCT may be of secondary affectability On identification about inside divider thickening.

Previously, our study, those affectability for MDCT done identification and analysis the reason for the inside divider thickening might have been $82.2 \%$ and the specificity might have been 76 . $2 \%$ with $82 \%$ correctness. Yet all the The point when including the connected criteria for example, such that fat stranding or delicate tissue impostor lesions the affectability might have been expanded on get $93.1 \%$ yet the specificity at present those same and the correctness might have been expanded up to $86 \%$.

\section{Conclusion}

At finished properly, MDCT could help in the diagnosis, management, Also medicine of patients. MDCT could a chance to be utilized for organizing Also catch up observation about colorectal cancer, and in addition a developing part to broad cancellous screening. 


\section{References}

[1] M.Macari1 and Emil J. Balthazar, CT of Bowel Wall Thickening Significance and Pitfalls of Interpretation. American Journal of Roentgenology, vol. 176, pp. 1105-1116,2001.

[2] T.Fernandes, M.I.Oliveira, R.Castro, Bowel wall thickening at CT: simplifying the diagnosis . Insight imaging Apr, vol. 5, pp. 195-208, 2014.

[3] S.K.Boyd, D.O., D. Julia Cameron-Morrison, D.O., CT Imaging of Large Bowel Wall Thickening . JAOCR at, vol. 5( 2), pp. 14-22, 2016.
[4] R.Gore and R.Smithuis, Bowel wall thickening CT-pattern. AJR, vol. 22, pp.155-250, 2014.

[5] TC. Fernandes, R. Castro, D. Pinto, Bowel wall thickening - a complex subject made simple. Electronic Poster presented at 2011 ESGAR meeting doi,vol43,pp.247-250,2011.

[6] M. Macari, AJ. Megibow and EJ. Balthazar, A pattern approach to the abnormal small bowel: observations at MDCT and CT enterography. AJR Am J Roentgenol, vol. 188, pp. 1344, 2007. 